\title{
Biotically driven vegetation mosaics in grazing ecosystems: the battle between bioturbation and biocompaction
}

\author{
Ruth A. Howison, ${ }^{1,3}$ Han OlfF, ${ }^{1}$ Johan van de Koppel, ${ }^{1,2}$ and Christian Smit ${ }^{1}$ \\ ${ }^{1}$ Conservation Ecology, Groningen Institute for Evolutionary Life Sciences, University of Groningen, P.O. Box 11103, 9700 CC \\ Groningen, The Netherlands \\ ${ }^{2}$ Royal Netherlands Institute for Sea Research, P.O. Box 140, 4400AC Yerseke, The Netherlands
}

\begin{abstract}
Grazing ecosystems ranging from the Arctic tundra to tropical savannas are often characterized by small-scale mosaics of herbivore-preferred and herbivore-avoided patches, promoting plant biodiversity and resilience. The three leading explanations for bistable patchiness in grazed ecosystems are (1) herbivore-driven nutrient cycling, (2) plantgrowth-water-infiltration feedback under aridity, and (3) irreversible local herbivore-induced abiotic stress (topsoil erosion, salinity). However, these insufficiently explain the high temporal patch dynamics and wide-ranging distribution of grazing mosaics across productive habitats. Here we propose a fourth possibility where alternating patches are governed by the interplay of two important biotic processes: bioturbation by soil fauna that locally ameliorates soil conditions, promoting tall plant communities, alternating with biocompaction by large herbivores that locally impairs soil conditions, and promotes lawn communities. We review mechanisms that explain rapid conversions between bioturbation- and biocompaction-dominated patches, and provide a global map where this mechanism is possible. With a simple model we illustrate that this fourth mechanism expands the range of conditions under which grazing mosaics can persist. We conclude that the response of grazing systems to global change, as degradation or catastrophic droughts, will be contingent on the correct identification of the dominant process that drives their vegetation structural heterogeneity.
\end{abstract}

Key words: abiotic stress; bioturbation; bistable states; compaction; ecosystem engineering; grazed ecosystems; nutrient availability; patch conversion; soil amelioration; water infiltration.

\section{INTRODUCTION}

A striking convergence in community structure is found between geographically and climatically separated ecosystems that support large herbivores (Fig. 1A-G). In such grazing ecosystems, vegetation structure is often characterized by patchy mosaics of concurrent prostrate lawns and tall vegetation, each dominated by different plant species, as found in Arctic and temperate salt marshes (Looijen and Bakker 1987, McLaren and Jefferies 2004), temperate grasslands, and tropical savannas (Mack and Thompson 1982, McNaughton 1984, Belsky 1986, Frank et al. 1998). Such grazing lawns, ranging from a few to several hundred square meters, are often highly utilized by grazers, while the interspersed tall

Manuscript received 30 September 2016; revised 31 January 2017; accepted 6 March 2017. Corresponding Editor: Samantha K. Chapman.

Ruth A. Howison and Han Olff contributed equally to this work.

${ }^{3}$ E-mail: ruthhowison@gmail.com patches are much less visited. Thus far, this bistable state of patches found in grazing ecosystems has been explained by a number of different underlying processes. While evidence for each of these current interpretations has been found under specific conditions, they do not sufficiently explain the dynamic shifts between grazed lawns and tall, less utilized patches (Frank et al. 1998), and causal explanations are often of a more phenomenological than a mechanistic nature. Also, it is still poorly understood why these vegetation structures are found under widely varying environmental conditions.

In this paper, we present a novel conceptual model detailing the mechanisms driving relatively small-scale vegetation patch dynamics in grazing ecosystems. In contrast to previously accepted mechanisms, we illustrate how bioturbating soil fauna engineer conditions that promote and maintain patches of tall vegetation, which may include bunch forming grasses, herbs and shrubs. Additionally we show how the new mechanism can, alone or in synergy with previously described mechanisms, expand the range of conditions under which grazing mosaics can persist. 


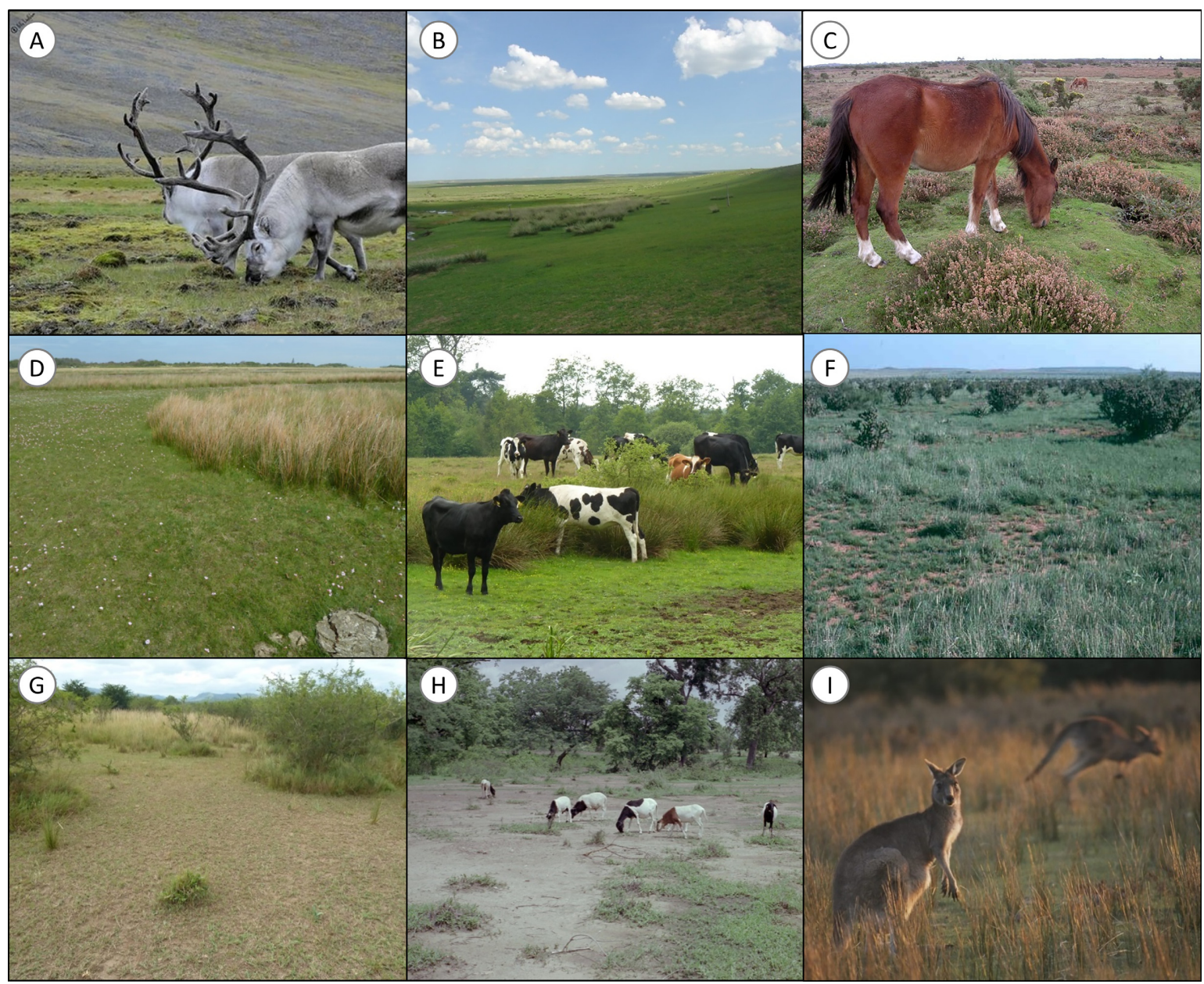

FIG. 1. Grasslands from nine geographically separated regions showing spatial mosaics of lawn and tall plant communities cooccurring where large herbivores are present. (A) Tundra, Arctic (source: ehow.com); (B) steppe, Mongolia (source: fao.org); (C) temperate heathland, UK (source: geographic.org.uk); (D) temperate salt marsh, northwestern Europe (photo: Ruth Howison); (E) temperate grassland, northwestern Europe (photo: Han Olff); (F) mixed prairie, south-central United States, Texas (source: fao.org); (G) semi-tropical savanna, Southern Africa (photo: Ruth Howison); (H) dryland, Sahel (photo: Johan van de Koppel); (I) temperate savanna, southeastern Australia (source: nationalgeographic.com).

Traditionally the dominant role of bioturbators in driving spatial structure of habitats has mostly been highlighted in marine environments (Meysman et al. 2006, Kristensen et al. 2012), with burying sea urchins, polychaete worms, bed-forming bivalves, and crustaceans as main actors. Despite early attention to the subject by Darwin (1881), the role of bioturbation in terrestrial systems is only recently receiving considerable attention, particularly in driving biogeomorphological and biogeochemical processes (Wilkinson et al. 2009, Butterfield 2011). In this, small mammals, earthworms, termites, and ants have been identified as key players (Jones et al. 1994). Bioturbating soil fauna alter the physical soil structure by loosening the soil (Wilkinson et al. 2009), and reversing the impacts of large grazers that induce abiotic stress through soil compaction. Bioturbating soil organisms predominate within the biomantle of the Earth's surface, the layer of topsoil separated from the lower subsoil layers by a basal stone layer. Estimates for the magnitude of impact soil organisms exert on the biomantle (mounding, mixing, and burial) range from 3 to $53 \mathrm{Mg} \cdot \mathrm{ha}^{-1} \cdot \mathrm{yr}^{-1}$ of processed soil for the temperate regions and between 730 and $1100 \mathrm{Mg} \cdot \mathrm{ha}^{-1} \cdot \mathrm{yr}^{-1}$ in the humid tropics (Wilkinson et al. 2009). Therefore, bioturbation can lead to more benign soil conditions through "decompaction," increasing macroporosity and thus water infiltration (Abdelmagid et al. 1987, Howison et al. 2015) and promoting root penetration (Wilkinson et al. 2009) of thickerrooted, taller-growing, plant species (Syers and Springett 1984, Joschko et al. 1989, van der Plas et al. 2013).

Bioturbating soil fauna are integral in many ecosystems and therefore are not mutually exclusive to existing hypotheses (Jones et al. 1994). Hence, we explain how the inclusion of bioturbation alters the predicted outcomes of leading hypotheses on bistability in grazed 
ecosystems, such as lawn formation through local nutrient feedbacks (McNaughton et al. 1989), sudden and irreversible vegetation shifts through hydrological modification (Rietkerk et al. 2004) or through promoting soil salinity by grazers (McLaren and Jefferies 2004, Jefferies et al. 2006). We will show that bioturbation provides a strong mechanism for reversal of stressful conditions for plants in grazing ecosystems, preventing permanent and large-scale degradation of ecosystems, and maintaining dynamic patterns in vegetation structure under a wide range of conditions found across the globe.

\section{Bioturbation and Herbivore-Plant QuAlity FeEdBACK}

The classic mechanism for patch bistability in grazed ecosystems focuses on the formation of grazing lawns alternating with tall vegetation patches, and originates from work in African savannas (McNaughton 1984, Hagenah et al. 2009; Fig. 1G). Here, it was suggested that short stature, high forage quality, grazing lawns are created and maintained by locally concentrated herbivore pressure; plants compensate for the loss of aboveground biomass through the production of young, high quality, vegetative regrowth (Archibald et al. 2005). Grazing herbivores spend an increasing proportion amount of time in preferred grazing patches (Howison et al. 2015), therefore increasing urine and dung inputs (Ruess and McNaughton 1987). In addition, repeated visits by herds to palatable plant-dominated patches exacerbate these effects, as urine deposition in these preferred areas promotes nutrient-rich plant growth (McNaughton 1984). According to this herbivore-plant-quality feedback hypothesis, the abundance of grazing lawns relative to tall patches will increase with increasing herbivore pressure, until a stable community of extensive grazing lawns over large spatial extents is reached. To illustrate the basics of this process, Box 1A shows a simple model that captures this mechanism, which is graphically shown in Fig. 2A. Contiguous, larger-scale lawn and tall plant communities arise from this process (not the often-observed small-scale heterogeneity [Kuijper and Bakker 2003]) because increased productivity, within tall patches, leads to decreased forage quality due to increased investments in structural tissues (e.g., lignin and cellulose), necessary to support taller aboveground biomass (Olff et al. 1997). Consequently herbivores avoid tall vegetation and concentrate on the lawns. Also, this mechanism, based on local promotion of nutrient cycling, does not address the generally observed shifts in community composition in response to grazing where patches are predicted to be static (Milchunas et al. 1988, Frank et al. 1998) or the associated changes in soil physical structure. Furthermore, the notion that tall plants become shorter through defoliation might be too simple; tall plants are frequently replaced by prostrate lawn species that can cope with increased grazing intensity (Milchunas et al. 1988) and with changes to soil structure through compaction (Schrama et al. 2012b) leading to less soil aeration and water infiltration. In addition, lawn vegetation, frequently visited by large herbivores, incurs trampling that crushes soft-bodied soil fauna and reduces habitable soil space by collapsing soil pores and channels, resulting in locally decreased densities of soil fauna (Schrama et al. 2012b, Howison et al. 2015), thereby reducing their bioturbating effects. This speeds up soil compaction and decreases water infiltration (Howison et al. 2015), hence inducing (biotic-driven) local drought conditions. In nutrient-based grazing lawns, the eventual return of taller plant species is often simply attributed to patch choice of grazing herbivores (moving to a more preferred patch locally or seasonal migration) and resulting in increased light competition by taller growing species (Frank et al. 1998). However, bioturbation provides a novel mechanistic explanation for the active reversal of the compacting effects of large herbivores through burrowing, nesting, and foraging activities that occur even in the permanent presence of grazers (Howison et al. 2015). As illustrated using a model in Fig. 3B, the addition of bioturbation can enlarge the range of conditions under which bistability of patchiness within a grazed ecosystem is expected. Thus, with the addition of bioturbation (soil amelioration by soil fauna), tall plant communities can invade lawns under a wider range of environmental conditions, which fits field observations.

\section{Bioturbation and the Water-Infiltration Feedback}

Growing attention for the effects of climate change on grazing ecosystems has stimulated the development of hypotheses for patchiness based on plant biomass dependency of water infiltration (van de Koppel et al. 1997), where plant productivity decreases at very intense herbivory. In many semiarid regions where plants are waterlimited, vegetated patches are observed to promote the infiltration of water. Plants increase water infiltration by intercepting rainfall, and water is channeled into the soil via root channels that improve soil structure and water holding capacity (Dexter 1991, Rietkerk and Van de Koppel 1997). In such systems, herbivory not only reduces plant biomass, but also leads to diminished plant production and hence less water infiltration, resulting in alternating bare and vegetated patches (HilleRisLambers et al. 2001, Kéfi et al. 2007). These types of scale dependent feedbacks, where individual plants profit from nearby plants but compete for resources with individuals farther away, can lead to the formation of relatively large scale spatial patterns (Fig. 1H) at the landscape scale (Klausmeier 1999, HilleRisLambers et al. 2001). Water infiltration is promoted by the presence of vegetation, and individual plants close together benefit from this increased water availability. However, with increasing distance, water availability diminishes and competition for water becomes important (Rietkerk et al. 2000, HilleRisLambers et al. 2001). At the landscape scale these local feedbacks between individual plants promote mosaic formation of alternating vegetated and bare patches, where surface run-off from 


\section{Box 1. Modelling Conditions that Cause Spatial Heterogeneity in Grazing Systems}

To explore whether vegetation will develop into a dense stand or a short-grazed sward, or a degraded bare soil, we consider the balance between plant production and offtake by the herbivores. These two processes, both functions of plant biomass $P$ and herbivore density $H$, can be described as functions $F(P)$ for plant production and $C(P, H)$ for herbivore consumption. The rate of change of plant biomass on a specific small-scale location (a $1-\mathrm{m}^{2}$ patch), can be described as $d P / d t=F(P)-C(P, H)$. The classic logistic growth equation $F(P)=r(1-P / K) P$ describes plant production as a function of standing plant biomass, where $r$ is the intrinsic (maximal) growth rate of the vegetation when unlimited by resources or competition, and $K$ is the maximal standing biomass. In the logistic growth equation, per capita plant growth diminishes as plant biomass increases, for instance, through self-shading or through leaf maturation. As a consequence, grazing will increase per capita plant growth through lowering the standing biomass, as observed in a range of studies (Dyer et al. 1993).

We analyze under which conditions this type of model shows two stable states, which could lead to bimodal patchiness of short-grazed and tall vegetation. We explored this using a bifurcation analysis of the models, comparing the effects of alternative mechanisms on the parameter ranges for which alternate stable states are found. We focused on two parameters that are key environmental drivers of local patchiness: maximum plant standing biomass $K$ (reflecting differences in rainfall or soil fertility) and herbivore density $H$ (reflecting different stocking rates). For simplicity of the analysis, herbivore abundance is kept constant. In our model analysis, we did not use parameter values specific to any of the real-world system. Rather, we used an abstract set of parameters, comparing how the models differ in functioning when the processes discussed in this paper are added. Therefore the models differ only in the processes they describe and are not restricted to a specific grazing ecosystem, e.g., temperate or tropical grasslands.

\section{A. Herbivore-plant-quality feedback}

The functional response of herbivores, i.e., consumption per unit herbivore as a function of plant biomass, follows a hump-shaped curve where intake increases as plant biomass increases (Fryxell and Sinclair 1988, van de Koppel et al. 1996), but shows a decline at high plant biomass due to the effect of forage maturation on palatability (van der Wal et al. 1998). A suitable formulation that generates such a relation is $C(P, H)=c\left(P-P_{\min }\right) /\left(P-P_{\min }+a\right) e^{-b\left(P-P_{\min }\right)}$, where $c, a$, and $b$ are non-mechanistic parameters that define the shape of the consumption function, and $P_{\min }$ is the minimum plant biomass needed for consumption to be possible (i.e., for the herbivore population to persist). Note that in this formulation, we presume that reduction of plant biomass below the maximum standing crop $K$ results solely from grazing.

For a specific range of parameter values, two stable states can occur in this model (Fig. 2A), reflecting heterogeneity at the patch level. Small initial differences in plant biomass can lead to the development of either a high plant biomass, low plant quality or to a low biomass, high quality state. This configuration provides an explanation for patchiness with a bimodal distribution of biomass, typical of many grazing systems. Based on this simplified model, we add more complexity in the next steps.

\section{B. Water-infiltration feedback}

A spatially implicit reduction of plant growth due to limited water availability at low plant biomass (as the water runs off to high biomass patches) provides an alternative mechanism for the occurrence of alternating patches of vegetation interspersed with bare soil in semiarid grazing systems (Rietkerk and Van de Koppel 1997, van de Koppel et al. 1997). The reduction of plant growth can be incorporated in the plant growth function $F(P)$ of the general model using the following formulation: $F(P)=r(1-P / K) P e^{s P}$, where $s$ captures the reduction of plant growth at low plant biomass. In Fig. 2B, this reduction can cause alternate stable states and hence patchiness even in the absence of the plant-quality feedback. Even in the simplest case of a linear functional response without levelling off to carrying capacity, two stable equilibria are found, one at zero plant biomass characterized by a bare, sealed soil, and one at high plant biomass with ample water infiltration. This model is equally valid for other systems where deterioration of abiotic conditions reduces plant growth, e.g., accumulation of salt at low plant biomass.

bare patches benefits vegetated patches (Rietkerk et al. 2000, Kéfi et al. 2007). Models that implicitly capture such mechanisms (Box 1B) illustrate that the range of parameter combinations for which bistability is found in this case is potentially broader than for the herbivore-plant-quality feedback hypothesis (Fig. 2A), emphasizing that water infiltration feedbacks can be an important driver of vegetation patchiness in arid or semiarid regions (Fig. 2B).

Soil patches that become bare due to intense grazing also become resistant to water infiltration due to crusting, 


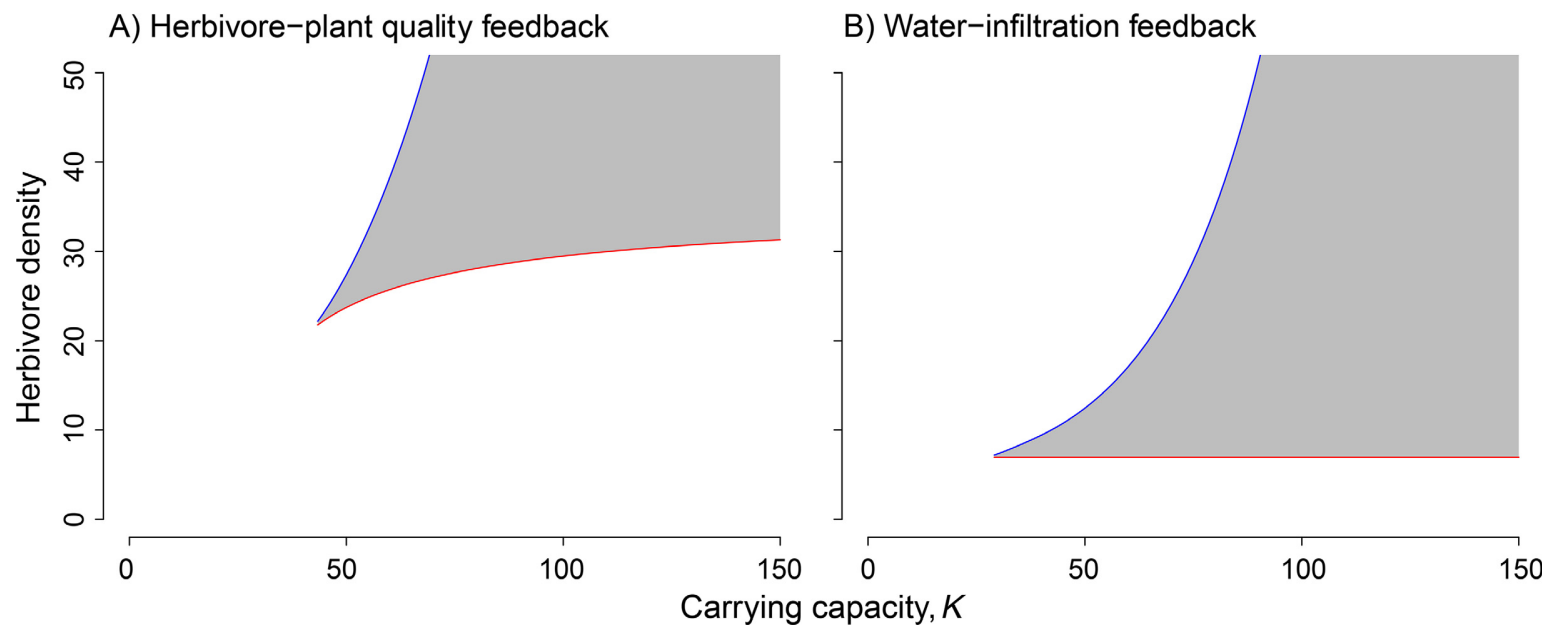

FIG. 2. Phase planes depicting the bifurcation analysis of simple plant-herbivore models, showing the more classical (A) herbivore-plant-quality feedback and (B) water-infiltration feedback.

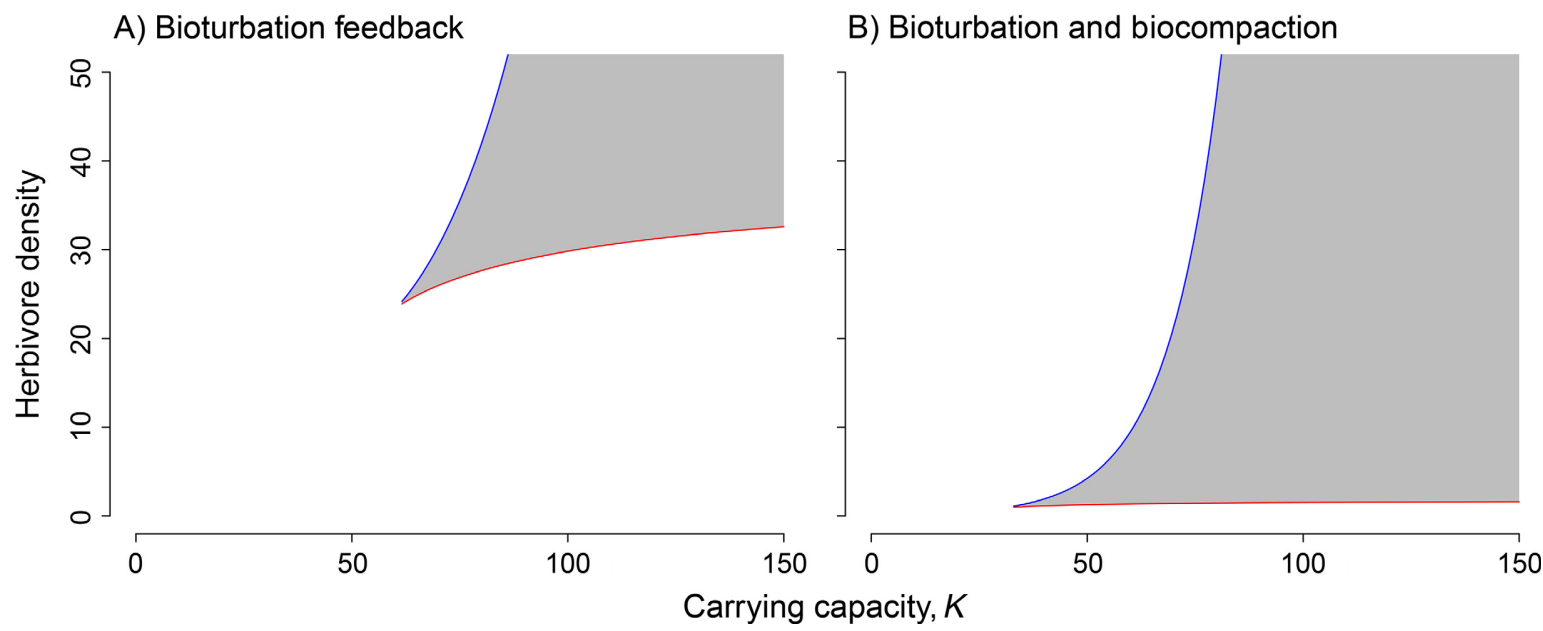

FIG. 3. Phase planes depicting the bifurcation analysis of plant-herbivore models with bioturbation, showing that the interplay between bioturbation and biocompaction strongly expands the conditions under which heterogeneity can persist in grazing ecosystems with (A) only bioturbation feedback and (B) the consequence of combining bioturbation and biocompaction feedbacks.

caused by increased surface temperatures, increased evaporation, high salinity (Jefferies et al. 2006), and microbial products (extracellular polymeric substances; Issa et al. 1999). Therefore water does not infiltrate in bare patches but runs off from bare soil toward vegetated patches, thereby improving water availability (Rietkerk et al. 2000). Vegetation mosaics of this nature buffer against complete irreversible transitions to alternate states of bare soil (HilleRisLambers et al. 2001). For instance, under decreased grazing pressure, the still-vegetated tall patches (refuges for grazing-intolerant plants) may expand through clonal growth, positive feedbacks of locally improved water availability, and nutrient supplies provided by the parent plant body. However, exceeding critical grazing pressures and extreme weather conditions (Van de Koppel et al. 2005) may disrupt patch stability and undo the benefits of the positive associations, which may then lead to irreversible vegetation collapse (Kéfi et al. 2007). Such overgrazing can lead to a uniform degraded bare state with no vegetation or mosaics. Whether the predictability of the occurrence of these regime shifts can be inferred from a snapshot of the patch size distribution, or requires deeper research in mechanisms and dynamics, is still a topic of debate (Kéfi et al. 2007, Maestre et al. 2009, Maestre and Escudero 2010).

In sensitive, highly stressful environments such as deserts and Arctic salt marshes (McLaren and Jefferies 2004, Jefferies et al. 2006), other types of seemingly irreversible soil modifications are found (McLaren and Jefferies 2004, Jefferies et al. 2006, Schrama et al. 2012b). In intensely grazed coastal systems, soil properties can be irreversibly and physically altered once local intense grazing and trampling leads to loss of the upper organic layer and bare soil becomes hyper-saline (McLaren and 
Jefferies 2004). Soil compaction through intensive grazing can also lead to decreased soil porosity, aeration, and nutrient mineralization and hence lower nutrient availability to plants, especially on fine-textured soils (Schrama et al. 2012b, 2013). In sensitive ecosystems with extreme seasonal variation and low primary productivity (e.g., deserts and Arctic salt marshes) recovery is slow, especially where grazing intensity remains high. Only the long-term removal of grazers and allowing for soil recovery over decades will facilitate the return of a vegetated state (Jefferies et al. 2006). Thus, according to this explanation, vegetation recovery is only possible through long-term geomorphic and soil-formation processes. However, soil amelioration through bioturbation is an alternative mechanism that may greatly enhance the recovery to a vegetated state by improving water infiltration (Dexter 1991), aerating the soil, and therefore improving nutrient mineralization rates. This was shown in exclosure experiments in riverine grasslands (Bakker et al. 2004) and in European salt marshes (Schrama et al. 2012a) resulting in increased plant performance. Although higher plant biomass may decrease plant and litter quality due to competition for light, this is unlikely to be slowing down nutrient cycling due to the promoting impact of macrodetrivores on decomposition rates (Scheu 2003, Schrama et al. 2015).

\section{A Novel Mechanistic Explanation: Bioturbation vs. Biocompaction}

Here, we propose a new combined set of mechanisms for maintaining bistable patchiness in grazing systems based on the opposing impact of bioturbating and biocompacting organisms. Bioturbating earthworms, termites, amphipods, millipedes, and enchytraeids (pot worms) have a profound and opposite impact on soil biophysical structure and chemical properties than soil-compacting large herbivores (Lawton 1994, Jouquet et al. 2006), and hence can play a key role in contributing to grazing mosaics. Such bioturbators increase the macroporosity through channeling and induction of soil aggregates through their feces (Joschko et al. 1989). This positively affects the availability of oxygen and water for nutrient mineralization, thus positively affecting nutrient uptake by plants and hence promotes aboveground plant productivity (Curry and Boyle 1987), giving tall, lightcompetitive, plant species an advantage. Bioturbation in itself can generate multiple stable states in vegetation structure in plant-herbivore models and hence explain bimodal patchiness in vegetation structure (Conditions causing spatial heterogeneity in grazing systems: The added value of bioturbation: Bioturbation feedback). However the parameter space within which this is possible is

\section{Box 2. Conditions Causing Spatial Heterogeneity in Grazing Systems: The Added Value of Bioturbation}

In model terms, the bioturbation feedback can be illustrated as a positive effect of plant biomass on permeability of the soil that increases toward higher plant biomass, e.g., through direct effects of roots or through indirect action of soil fauna that profits from litter formed at high plant biomass. The net effect of these bioturbation mechanisms is very similar to the phenomenological effect of higher plant biomass promoting its own growing conditions (and thus per capita growth rate) in the water-infiltration feedback model.

\section{A. Bioturbation feedback}

A simplified formulation of the effect of bioturbation on plant growth can be captured by the growth function $F(P)=r(1-P / K) P e^{s P}$, where $s$, in this model, depicts the effect of the feedback between increased plant biomass through increased bioturbation. Note that we strictly link the reduction of bioturbation, induced by direct biocompaction by herbivores, with their grazing activity, which might be uncoupled in more complex mathematical studies of this problem. Obviously, as this feedback is mathematically similar to the increased infiltration feedback, it can explain the generation of alternate stable states and associated patchiness in grazing systems, even in the absence of the plant-quality feedback. The range of parameter values for which this occurs is, however, relatively limited (Fig. 3A).

\section{B. Combining bioturbation and quality feedbacks}

In many, if not all, terrestrial grazing systems, both the bioturbation and the quality feedback will be present, and both processes will interact to affect the patch dynamics. Analysis of the balance of plant growth $F(P)=r(1-P / K) P e^{s P}$ and herbivore consumption $C(P, H)=c\left(P-P_{\min }\right) /\left(P-P_{\min }+a\right) e^{-b\left(P-P_{\min }\right)}$ reveals that these two process apparently enforce each other, which is suggested by a large distance between plant growth and herbivore consumption curve on both sides of the threshold equilibrium (result not shown). Hence, the quality and the bioturbation feedback amplify each other, causing alternate stable states for a wider range of environmental conditions (Fig. 3B). This amplifying mechanism is easy to see: bioturbation promotes the biomass in tall patches that drives herbivores increasingly to the grazing lawns, where biocompaction therefore becomes stronger. On the other hand, biocompaction promotes the attractiveness of the lawns for herbivores that thus increasingly abandon the tall vegetation. In more general terms, multiple stable states occur under a wider range of conditions when each alternative state is more self-promoting. 
rather limited, indicating the importance of the interaction between the bioturbation and other heterogeneitygenerating mechanisms (Fig. 3A).

Recent studies have shown that herbivore-driven soil compaction through intensive and repeated trampling (Donkor et al. 2002, Schrama et al. 2012b) is an important mechanism that counteracts bioturbation. Hence, this process should be incorporated in the theoretical framework for bistability in vegetation patchiness. Soil compaction by trampling herbivores leads to drier soils, as the infiltration rate is lowered (Belsky 1986, Rietkerk et al. 2000, Veldhuis et al. 2014), bare soil evaporation is increased due to higher soil temperatures (Rietkerk et al. 2000) and N mineralization may be reduced as a result.

Only specific plant species, notably "lawn grasses," are able to cope with both abiotic and herbivory stress due to their physiognomic characteristics, which reduce the negative impacts of organ loss resulting from both low moisture and herbivory stress (van der Plas et al. 2013). These characteristics include compact basal meristems, small stature, prostrate growth form, high shoot density, deciduous shoots, belowground nutrient reserves, and rapid growth (Milchunas et al. 1988). In addition, geophytes (as Liliaceae), i.e., plant species with extensive belowground storage organs (bulbs) that emerge only during short periods at the peak of the growing season, are found in these communities. Soil bioturbation by soil fauna (as ants, termites, moles, prairie dogs, gophers) and compaction by large herbivores in grazing ecosystems can be seen as selfstabilizing forces at the patch scale. In this, large grazing herbivores maintain lawn patches while bioturbating soil fauna stimulate plant biomass production (Box 2B), giving the widest possible parameter space for bistability to occur because the two dominating basic processes reverse the effects of each other (Fig. 3B). Therefore the activities of both soil fauna and herbivores operate within the same landscape by promoting their own resources and maintaining patches in alternative states and thereby spatially segregating among different patch structures. Table 1 features globally separated case studies that support bioturbation vs. biocompaction type mechanisms generating bistable patchiness in grazing ecosystems.

This novel mechanistic explanation for patch formation in grazing ecosystems has three key elements: (1) bioturbation by soil fauna whose foraging, tunneling, and nesting activities loosen up soil, (2) biocompaction by large herbivores that compact soil with their large body mass relative to hoof area, and (3) patch conversion mechanisms that promote spatial and temporal dynamics by inducing switches between bioturbation- and biocompaction-dominated states. In Fig. 4, we outline our new conceptual model for how bioturbation and biocompaction interact in causing vegetation structural mosaics. A thorough understanding of this interplay requires further insight in the nature of both bioturbation and biocompaction, and in the mechanisms that cause a bioturbated state to change into a biocompacted state and vice versa (patch conversion mechanisms).

\section{The nature of bioturbation}

Bioturbation (Fig. 4A) alters a number of key ecosystem processes, in particular increasing soil macroporosity, permitting penetration of larger diameter roots (Joschko et al. 1989), and increased infiltration of water (Howison et al. 2015) leading to less run-off and deeper penetration through the soil profile and leaching of accumulated salts (Abdelmagid et al. 1987) and improved gaseous exchange with the atmosphere, favoring oxic microbial nutrient mineralization (Meysman et al. 2006, Schrama et al. 2013). Nutrients are therefore more deeply cycled in bioturbated soils and run-off of organic matter is prevented, creating a positive feedback of bioturbating soil fauna on nutrient availability for the vegetation (Wilkinson et al. 2009). Tall, more light-competitive plants that grow in bunch forms or propagate through short rhizomes (van der Plas et al. 2013), profit from the ameliorated abiotic conditions. Such tall light-competitive plants invest their carbon resources in aboveground structures and can then outcompete lawn species through shading (Milchunas et al. 1988). The resulting high concentrations of structural components (lignin and cellulose) in the shoots causes these plants to be generally of lower forage quality for herbivores, making their leaves more difficult to digest, albeit often a necessary component for large herbivores to bulk up their food intake (Iason and van Wieren 1999). Also, these bulk feeders can harvest a lot of biomass in a relatively short time in these tall patches, resulting in less biocompaction than in the lawn types (less trampling per unit time). Therefore patches that contain these plants are less intensely and less frequently utilized by herbivores (Dumont et al. 2007) and plants and associated bioturbating soil fauna can persist under the resulting moderate to low average trampling pressure. As not all plant biomass produced is grazed in these tall patches, standing dead plant material accumulates aboveground creating a shady and moist microclimate, and turns into leaf and stem litter that is collected by soil fauna and buried, thereby further enhancing microbial abundance and bioturbating soil fauna in return (Lopez et al. 1977, Sharma et al. 2005). In addition, given that some bioturbators are (partly) herbivorous (e.g., some species of gophers, voles, termites, or ants) they may themselves directly alter the plant community composition by preferential feeding. For example, the marine amphipod Orchestia gammarellus turned out to selectively feed upon the grass Festuca rubra under high stressful conditions, changing the interaction outcome between two dominant grass species (Howison et al. 2016b).

\section{The nature of biocompaction}

Relative to the role of herbivores in promoting nutrient cycling and water-infiltration feedbacks, their importance as biocompaction agents have so far been underestimated in our view (Fig. 4B). Plant biomass produced in grazing lawns is mostly broken down in the gut of the herbivores 
TABLE 1. Globally separated case studies that support bioturbation vs. biocompaction-type location mechanisms generating bistable patchiness in grazing ecosystems.

\begin{tabular}{|c|c|c|c|c|}
\hline Key processes & Location & Bioturbators & Biocompactors & Reference \\
\hline Grazing lawn formation & $\begin{array}{l}\text { Serrengetti, Savanna east } \\
\text { Africa }\end{array}$ & & $\begin{array}{l}\text { large wild } \\
\text { ungulates }\end{array}$ & McNaughton (1984) \\
\hline $\begin{array}{l}\text { Soil structure, nutrients, plant } \\
\text { growth, roots, soil fertility }\end{array}$ & review & earthworms & & $\begin{array}{l}\text { Syers and Springett } \\
(1984)\end{array}$ \\
\hline Increased productivity & $\begin{array}{l}\text { raised bog, Clonsast County, } \\
\text { Offaly }\end{array}$ & earthworms & & Curry and Boyle (1987) \\
\hline $\begin{array}{l}\text { Low marsh species return } \\
\text { under grazing }\end{array}$ & $\begin{array}{l}\text { Schiermonnikoog, island salt } \\
\text { marsh, northwestern Europe }\end{array}$ & & cattle & $\begin{array}{l}\text { Looijen and Bakker } \\
\text { (1987) }\end{array}$ \\
\hline $\begin{array}{l}\text { Earthworm burrows, casts, } \\
\text { macropores, bulk density, soil } \\
\text { compaction, water movement }\end{array}$ & laboratory experiment & earthworms & & Joschko et al. (1989) \\
\hline $\begin{array}{l}\text { Low marsh species return } \\
\text { under grazing }\end{array}$ & $\begin{array}{l}\text { Leybucht, mainland salt marsh, } \\
\text { northwestern Europe }\end{array}$ & & cattle & Andresen et al. (1990) \\
\hline $\begin{array}{l}\text { Autogenic and allogenic } \\
\text { ecosystem engineering by } \\
\text { organisms }\end{array}$ & global review & $\begin{array}{l}\text { marine, terrestrial, } \\
\text { and avian }\end{array}$ & $\begin{array}{l}\text { elephant, } \\
\text { crocodiles }\end{array}$ & Jones et al. (1994) \\
\hline $\begin{array}{l}\text { Change in basal area of } \\
\text { different grass species }\end{array}$ & $\begin{array}{l}\text { Gazankulu, grassland, South } \\
\text { Africa }\end{array}$ & & cattle & O’Connor (1994) \\
\hline $\begin{array}{l}\text { Effects of invertebrates and } \\
\text { herbivores }\end{array}$ & book on zoogeomorphology & invertebrates & herbivores & Butler (1995) \\
\hline Glades, wallows & $\begin{array}{l}\text { Mpala National Park, Savanna, } \\
\text { east Africa }\end{array}$ & & cattle, buffalo & Young et al. (1995) \\
\hline $\begin{array}{l}\text { Patchy vegetation height, } \\
\text { forage quality, grazing } \\
\text { intensity, patch avoidance }\end{array}$ & Buenos Aires, Argentina & & cattle & Cid and Brizuela (1998) \\
\hline $\begin{array}{l}\text { Prevent succession to shrub } \\
\text { land/woodland }\end{array}$ & $\begin{array}{l}\text { Konza Prairie, North America, } \\
\text { tall grass prairie }\end{array}$ & & bison, cattle & Knapp et al. (1999) \\
\hline $\begin{array}{l}\text { Herbivore aggregation } \\
\text { concentrates defoliation } \\
\text { pressure }\end{array}$ & $\begin{array}{l}\text { Schiermonnikoog, island salt } \\
\text { marsh, northwestern Europe }\end{array}$ & & $\begin{array}{c}\text { Dark-bellied } \\
\text { Brent Geese }\end{array}$ & Bos et al. (2004) \\
\hline Grazing lawn formation & $\begin{array}{l}\text { Kruger Park, Savanna, South } \\
\text { Africa }\end{array}$ & & $\begin{array}{l}\text { large wild } \\
\text { ungulates }\end{array}$ & $\begin{array}{l}\text { Grant and Scholes } \\
\text { (2006) }\end{array}$ \\
\hline Grazing lawn formation & $\begin{array}{l}\text { Benue National Park, North } \\
\text { West Africa }\end{array}$ & & hippo, kob & Verweij et al. (2006) \\
\hline $\begin{array}{l}\text { Ecosystem engineers, soil } \\
\text { ecology }\end{array}$ & review & $\begin{array}{l}\text { earthworms } \\
\text { ants, termites }\end{array}$ & & Jouquet et al. (2006) \\
\hline $\begin{array}{l}\text { Dung and urine soil } \\
\text { amendment, grassland soil } \\
\text { feedback, spatial variation, } \\
\text { trampling }\end{array}$ & $\begin{array}{l}\text { Finnish dairy cow } \\
\text { pasture }\end{array}$ & earthworms & cattle pasture & Mikola et al. (2009) \\
\hline $\begin{array}{l}\text { Bioturbation on soil formation } \\
\text { and soil structure, soil } \\
\text { production, soil creep, soil } \\
\text { carbon }\end{array}$ & review & $\begin{array}{l}\text { earthworms, } \\
\text { ants, termites }\end{array}$ & & Wilkinson et al. (2009) \\
\hline
\end{tabular}

and associated microflora instead of by free-living soil microbes, and nutrients are returned as urine and feces to the grazing area in mostly plant-available forms (Ruess and McNaughton 1987). For the same unit of biomass intake, herbivores will spend in total more time on high quality, low biomass lawns, compensating for the decreased bite size that can be realized in lawn vegetation by a longer daily foraging time (Iason and van Wieren 1999). Lawn grasses are especially well adapted to deal with the physical and abiotic conditions in these frequently grazed areas (Garibaldi et al. 2007, van der Plas et al. 2013). They are stoloniferous, storing much of their carbohydrates in the horizontal stolons (which helps to cope with trampling, as compared to vertical stem bases of tall grasses), and can cope with frequent defoliation by herbivory by rapid resprouting of photosynthetic material (Milchunas et al. 1988, Bardgett and Wardle 2003). In addition, the potential for rapid lateral vegetative expansion allows these plants to successfully compete for space that is opened up by the grazing herbivores (O'Connor 1994, Cumming and Cumming 2003). Fine adventitious root systems allow these plants to penetrate the decreased pore space resulting from compacted soil (van der Plas et al. 2013); the fine roots probably rapidly absorb water and nutrients that seep into the first few centimeters of surface soil. 

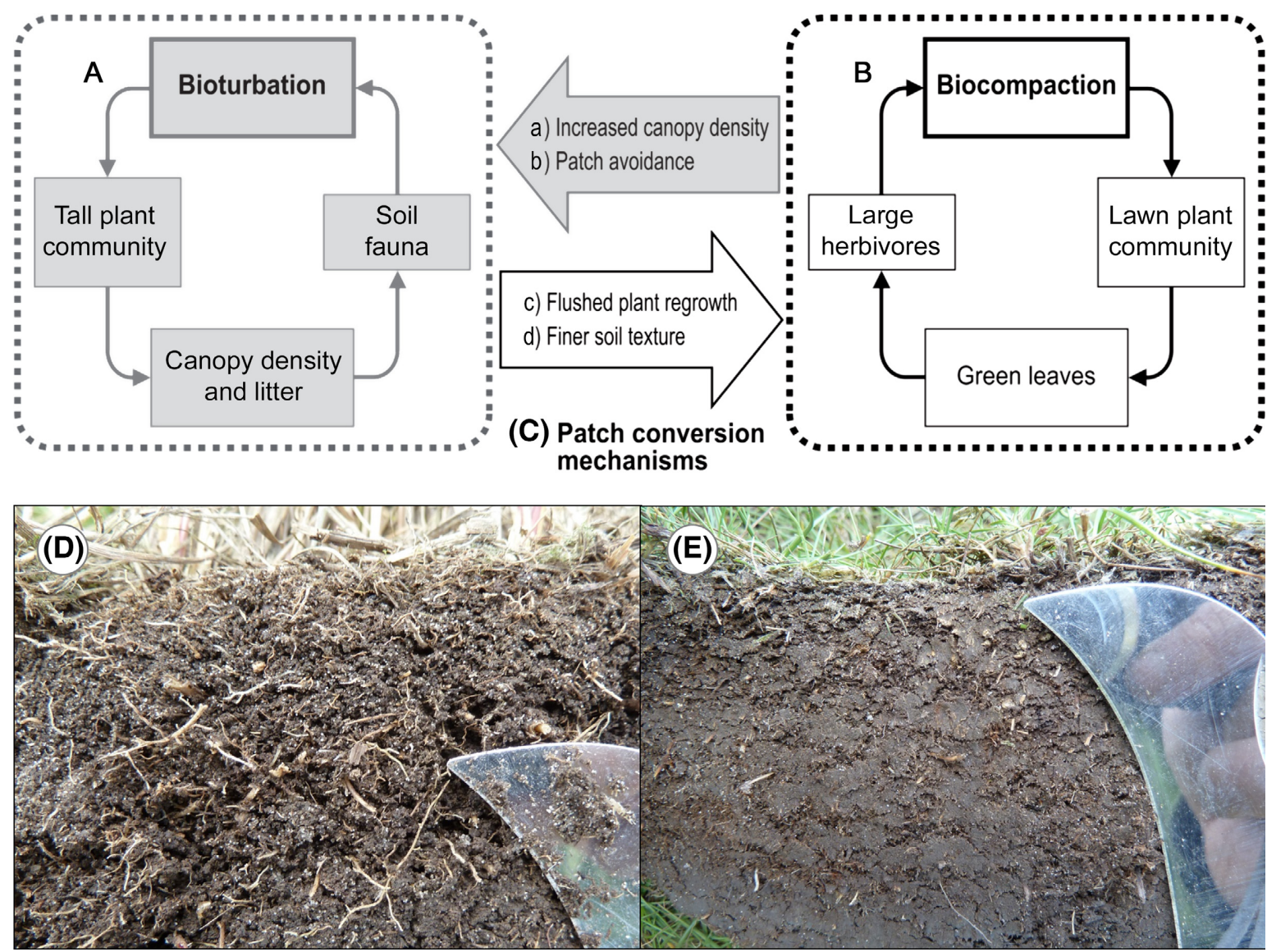

FIG. 4. A conceptual model explaining mechanisms promoting structural vegetation mosaics in grasslands showing basic processes. (A) Tall plant communities are promoted by bioturbating activities of soil fauna as the ecosystem matures. (B) Large grazers induce abiotic stress through trampling and compaction. (C) Patch conversion mechanisms: (a) lawn to tall, herbivore aggregation or seasonal migration releases defoliation pressure leading to increased biomass provides shade and increased litter, favorable for soil fauna; (b) lawn to tall, patch avoidance through plant defense (chemical or physical), presence of carcasses or dung; (c) tall to lawn, widespread flushed regrowth is highly attractive to large grazers; and (d) tall to lawn, bioturbating soil fauna (ants, termites, earthworms) locally bring fine particulate subsoil (clay, loam) preferentially to the surface over coarser particles (sand, gravel), and the resulting finer texture promotes compaction. The photos illustrate the major differences in soil structure resulting from the two main basic processes: (D) bioturbation, loose structured soil created by the higher prevalence of bioturbating soil fauna, and (E) biocompaction, compacted soil with compressed plant roots and reduced soil pore space created by a higher prevalence of large grazing herbivores. Photos by Han Olff.

\section{Patch conversion mechanisms}

A patch may either be a grazing lawn or a patch of tall plants, depending on initial conditions. The opposing and self-reinforcing mechanisms, bioturbation (through soil amelioration and increased plant productivity) or biocompaction (through grazing and trampling), maintain patches in a particular state. However, at the landscape scale, patches may become more or less attractive to gregarious herbivores. When patches become avoided or abandoned, plant biomass increases, promoting conditions for soil macrofauna, which then rapidly switch to a tall (unattractive to herbivores) patch structure. In Fig. 4C and illustrated in Fig. 5A-D, we outline a number of key mechanisms that can explain how patches of lawn plants and tall communities may dynamically revert into each other, relatively quickly shifting the balance from a herbivore/lawn grass-dominated, to a soil fauna/tall grassdominated community. The main mechanisms identified so far are (1) released defoliation pressure through aggregation or seasonal migration (Frank et al. 1998, Bos et al. 2004) leads to an increase in aboveground biomass that provides shade, moisture, and litter (Hacker and Bertness 1999), favorable for soil fauna; (2) large herbivores may avoid certain patches because of defense strategies of the dominant plants (chemical or physical; Bergvall et al. 2006), because of the presence of carcasses (Bump et al. 2009) Fig. 5A, dung (Cid and Brizuela 1998), or temporary local obstructions (fallen-over trees, temporary inaccessibility of sites during tidal inundations; Wilkinson et al. 2009), or due to perceived high predation risk (Hopcraft et al. 2010) in tall vegetation Fig. 5B; (3) flushed 
plant regrowth at the onset of spring following a harsh winter or after fire Fig. 5C provide the expansive availability of young green leaves attract large grazers (Archibald et al. 2005); (4) burrowing soil fauna bring fine particulate subsoil to the surface, which erodes, especially downslope, and forms a compacted crust (Wilkinson et al. 2009) (Fig. 5D).

Field experiments that exclude large herbivores are a good method to explore the time scale of the conversion of a biocompaction-dominated to a bioturbation-dominated state. Fig. 6 shows examples of such conversions that were studied by the authors in different ecosystems. In general, the more productive and the more clayey the soils are, the faster these conversions can happen. Under high rainfall $(800 \mathrm{~mm} / \mathrm{yr})$ and clayey soils, conversions from lawn grasses to bunch grasses were observed to happen in less than $3 \mathrm{yr}$ (Fig. 6A, B) while on more sandy soils (Fig. 6C) or in the presence of salinity stress (Fig. 6D), this took longer, up to $10 \mathrm{yr}$.
Case studies conducted by ourselves and colleagues are available from a few study systems that illustrate how the stepwise sequence of processes depicted in Fig. 4 create vegetation heterogeneity in the field. In our first example situated in European salt marshes (Fig. 6D), building on previous work (Schrama et al. 2012b, van Klink et al. 2015), we contrasted the status quo of physical conditions within lawn and bunch patches (Howison et al. 2015). We find $60 \%$ higher abundances of soil fauna in bunch patches than in lawn, where herbivores are excluded and conversely large herbivore presence was measured to be threefold higher in lawn patches compared to bunch patches. Using a multivariate approach, we could illustrate intrinsic differences between tall bunch patches and short lawn patches. In the tall bunch patches, we measured significantly higher aboveground biomass, as well as differences in environmental conditions such as lower canopy light penetration, higher soil air porosity and higher

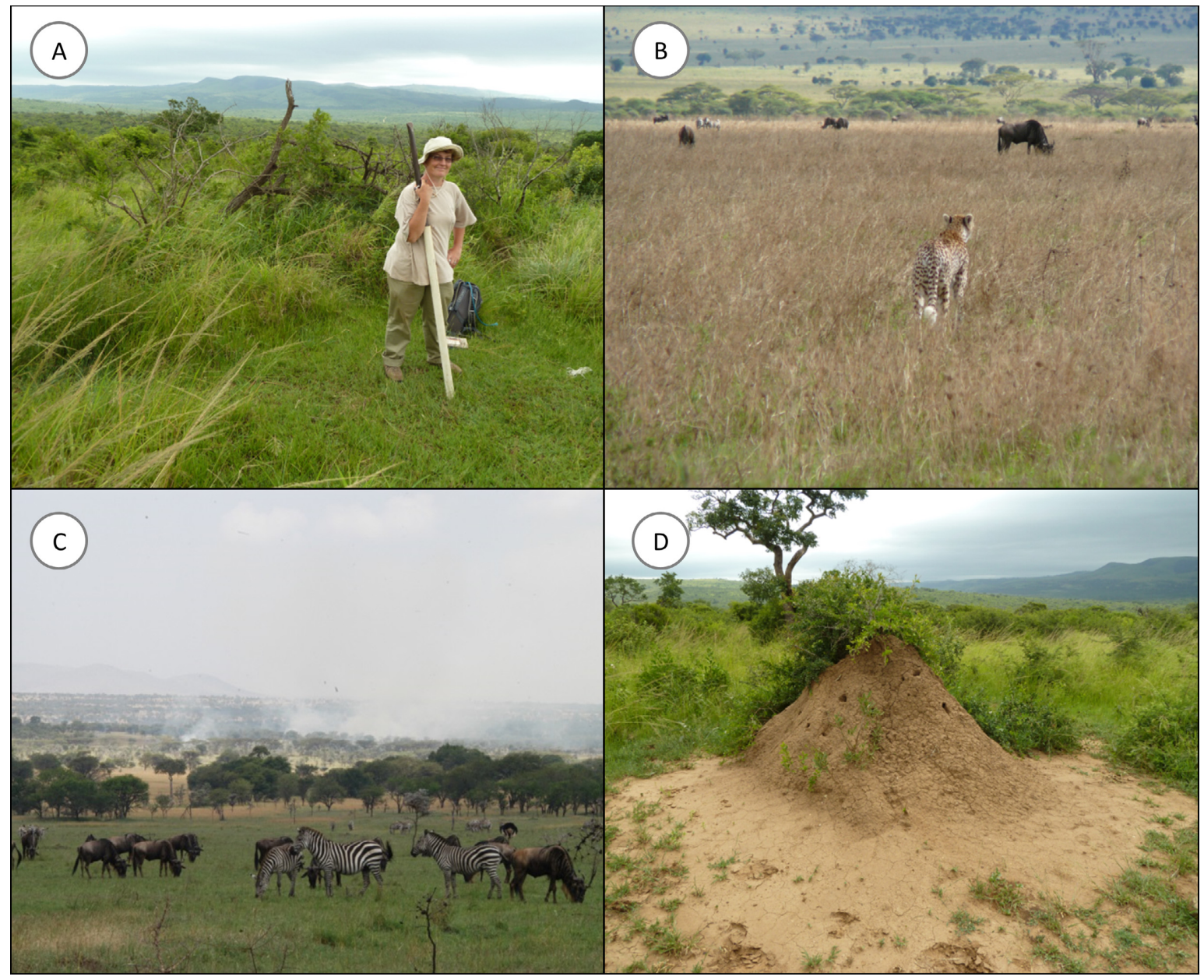

FIG. 5. Examples of factors leading to patch conversions in different directions. (A) Lawn to tall, spiny shrubs and dead wood locally promoting tall grasses and soil fauna in an African savanna, Hluhluwe-iMfolozi, South Africa. (B) Lawn to tall, nearby tall patches increase the predation risk for herbivores on lawn patches, driving them away in Serengeti, Tanzania. (C) Tall to lawn, multiple species of large herbivores aggregating on a recently burned area of previously tall vegetation in the Serengeti, Tanzania. (D) Tall to lawn, grazing lawn formation on clay accumulation downslope from a Macrotermes termite mound, Hluhluwe-iMfolozi park, South Africa. All photos by Han Olff. 


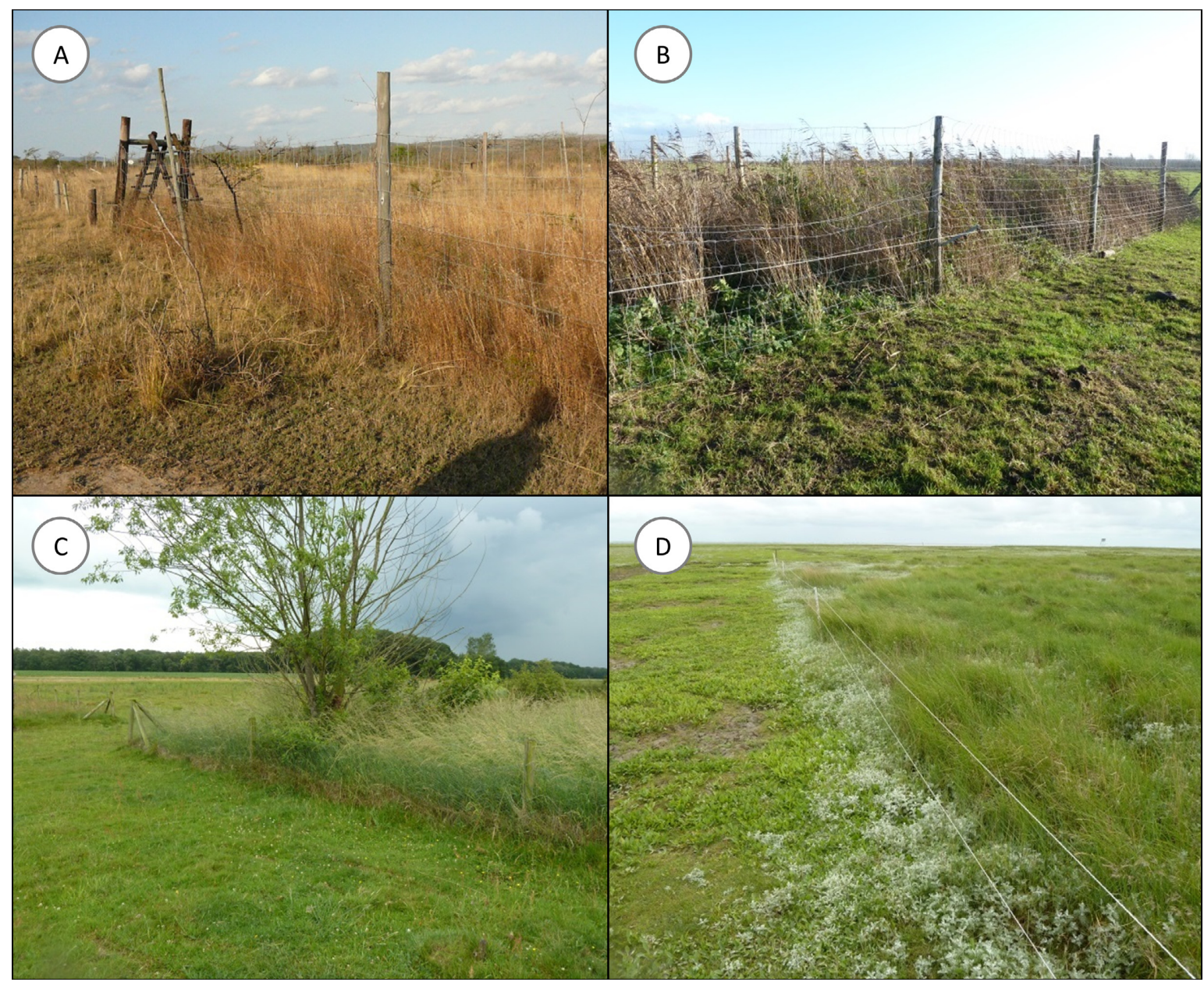

FIG. 6. Examples of the time scale of temporal change of shifts from a biocompaction-dominated to a bioturbation-dominated state upon excluding large grazers. In all cases fences were placed within homogeneous lawns. (A) Tropical savanna vegetation $(600 \mathrm{~mm} / \mathrm{yr}$ rainfall) in Hluhluwe-iMfolozi Park, South Africa, maintained by white rhino and impala, reverts to tall bunch grasses within $3 \mathrm{yr}$ by bioturbating earthworms and termites. (B) Temperate clay marsh ( $800 \mathrm{~mm} / \mathrm{yr}$ rainfall) of the Oostvaardersplassen, The Netherlands, maintained by cattle, reverts to tall grasses within $3 \mathrm{yr}$ by bioturbating earthworms and voles. (C) Temperate sandy floodplain grasslands ( $800 \mathrm{~mm} / \mathrm{yr}$ rainfall) of Junner Koeland, The Netherlands, maintained by cattle, reverts to tall bunch grasses within $10 \mathrm{yr}$ by bioturbating earthworms and voles. (D) Temperate saltmarsh $(800 \mathrm{~mm} / \mathrm{yr}$ rainfall) on Schiermonnikoog, The Netherlands, maintained by cattle, reverts to tall bunch grasses within $10 \mathrm{yr}$ by bioturbating amphipods and isopods. All photos by Han Olff. [Color figure can be viewed at wileyonlinelibrary.com]

available soil oxygen. In our second example, following the experimental work in the African savanna (Fig. 6A) by Cromsigt and Olff (2008), who showed patch conversion from a tall bunch community and maintenance of a short lawn community by aggregating large grazing herbivores, a conversion that persisted without any further manipulation for the $3 \mathrm{yr}$ of experimental observation. Experimentally and under natural field settings, we tested the hypothesis of patch reversal from lawn to bunch through the mechanism of herbivore patch avoidance (Howison et al. 2016a). Herbivore-avoided patches were created by replacing substantial quantities of large herbivore dung (20 kg per patch) to mixed bunch-lawn patches. After quantifying the colonization of dung patches by different groups of coprophagous macrodetritivores, we quantitatively compared our experimental patches to control conditions (without dung). Within a 12-week period, we found a $58 \%$ increase in tall bunch grass basal cover and an $80 \%$ increase in aboveground biomass, furthermore, the bioturbating activities of the soil fauna lead to 2.5-fold higher water infiltration rates, $20 \%$ higher soil organic matter, and 23\% higher soil macroporosity. Hence, evidence for the bioturbation-biocompaction mechanism is increasingly becoming available.

\section{Limitations to bioturbation vs. biocompaction patchiness: toward a global prediction}

As with any newly proposed ecological mechanism that generates heterogeneity or maintains biodiversity, it is 
important to explore under which range of global conditions, and hence where on the world map, it is expected to operate (although this is rarely done). For exploring the possible range of conditions where this bioturbation and biocompaction mechanism is found, we used the harmonized world soil database (HWSD) version 1.21 (Nachtergaele and Batjes 2012) to identify unsuitable soils; permafrost regions, organic soils (histosols or soils containing an organic matter content of $>20 \%$ dry mass), and sandy soil (with sand fraction $>70 \%$ and clay fraction $<15 \%$ ). Rainfall parameters were delineated using a global precipitation surface (Hijmans et al. 2005) representing limits to forage quantity and quality required to maintain large herbivores (data available online) ${ }^{4}$

Soil mineral composition (related to parent material), particle size distribution, and organic matter content are crucial to the compactability, water holding capacity and nutrient richness of the soil (Hoorman et al. 2009, Wilkinson et al. 2009, Veldhuis et al. 2014), and hence restrict where interacting bioturbation and biocompaction patchiness may occur. Recent work shows that sandy soils are hardly compactible compared to clay soil, due to differences in aggregate formation (Schrama et al. 2012b, Veldhuis et al. 2014). To illustrate this, Schrama et al. (2012b) and Howison et al. (2015) found large differences in environmental conditions between grazed and ungrazed treatments on clay soil but not on sand. Grazed clay soils had lower oxygen content and less air-filled pore space, inducing plant anoxia stress. Highly organic soils are also difficult to compact; they regain their original shape once heavy traffic has passed through (Hoorman et al. 2009). Permafrost soils, i.e., permanently frozen within the first $100 \mathrm{~cm}$ of the soil profile are also difficult to compact, either because of high organic matter content present (Tarnocai et al. 2009) or because topsoil freezing prevents compaction. In general, the more compactable the soil is, the stronger the contrasting effects of bioturbators and biocompactors, and thus more small-scale heterogeneity in vegetation structure is found. Little compaction is expected on sandy, organic, or frozen soils.

Rainfall is another factor that restricts where bioturbation-biocompaction-driven mosaics are expected. Rainfall determines the range of conditions under which large herbivores are found (Olff et al. 2002), and thus also where grazing ecosystems are expected. Specifically, large herbivore-dominated systems are generally found between 400 and $1200 \mathrm{~mm}$ of rainfall (Olff et al. 2002). Below this range, conditions are too arid to produce enough biomass to support diverse higher abundances of free-ranging large herbivores (Fryxell 1991), and above this range grasslands and savannas become unstable, and are replaced by closed woody canopies unless intensively managed with high stocking rates or fire (Sankaran et al. 2005, Lehmann et al. 2011). Above

\footnotetext{
${ }^{4}$ www.worldclim.org/bioclim
}

$1200 \mathrm{~mm} / \mathrm{yr}$ plant quality also declines to below the critical threshold that sustains large herbivores (Olff et al. 2002).

Fig. 7 shows how the overlay of these restrictions to bioturbation-biocompaction-driven vegetation mosaics works out at the global scale. It shows that grazing ecosystems with a key role of the mechanism proposed in this paper potentially occur across widespread areas of all continents, although not everywhere. Soil type, aridity, and excessive rainfall play a similar role in restricting the conditions where the proposed mechanism is likely to occur. In many parts of the globe, such as Europe, North America, China, and India, agriculture now dominates in areas for which heterogeneous grazing ecosystems are predicted to occur under natural conditions according to our "restriction approach."

\section{IMPLICATIONS}

We expect that our novel bioturbation-biocompaction mechanistic explanation for vegetation heterogeneity in grazing ecosystems will have major implications for various current ecological hypotheses. For example, it has important consequences for understanding the general direction of plant-plant interactions along environmental gradients (Howison et al. 2015, Soliveres et al. 2015). Previous work has shown that positive (facilitative) plant-plant interactions prevail under harsh conditions while negative (competitive) interactions dominate under more benign conditions (Bertness and Callaway 1994), also better known as the "stress gradient hypothesis." However, these general rules do not seem to apply in grazing ecosystems as positive interactions are also important under productive conditions (Crain 2008, Smit et al. 2009). Our bioturbation vs. biocompaction framework provides a new view on how herbivory affects the key processes determining plant community composition, through the important finding that stress in grazing ecosystems (e.g., drought or salinity) is not always externally imposed, but can also be generated in the system itself through biocompaction. Spatial heterogeneity in vegetation structure would therefore not be consistently predicted by underlying heterogeneity in resources (e.g., water, soil depth, nutrients) or along landscape stress gradients (e.g., rainfall, inundation), but rather by the strength of locally biotically induced/ameliorated stress conditions (Howison et al. 2015).

The novel insights in origins of vegetation heterogeneity outlined here can also help in promoting the sustainable use of grazing ecosystems. Specifically it is important to be able to distinguish between whether classic herbivore-plant quality feedbacks, classic waterinfiltration feedbacks, the interplay between bioturbation and biocompaction, or combinations of these processes are important. These different mechanisms result in quite different predictions on resilience and spatiotemporal dynamics. When long-term plant-quality feedback causes grazing lawns, these will generally stay 


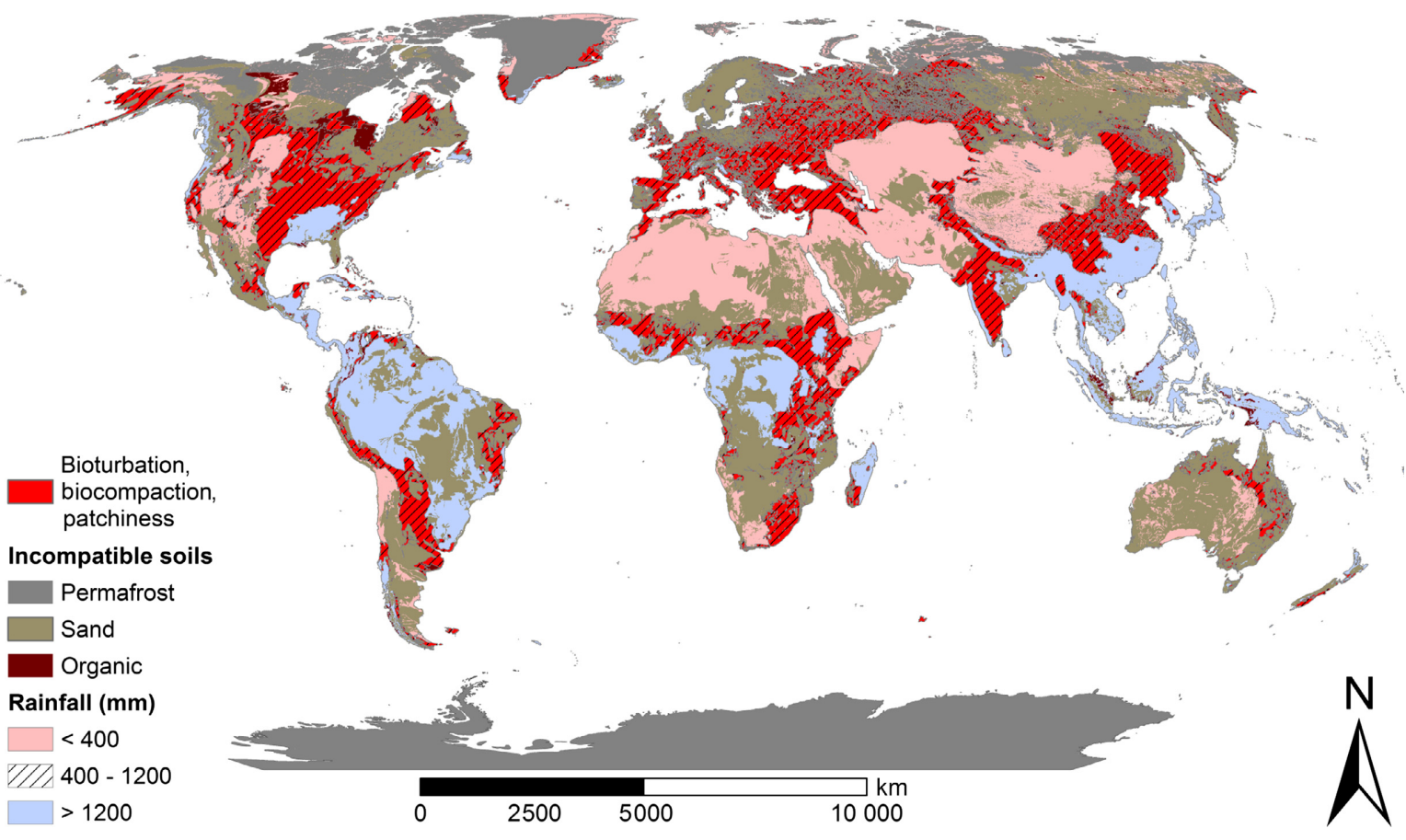

FIG. 7. Global prediction of the regions where patchiness generated by bioturbation and biocompaction is possible, eliminating for unsuitable conditions, specifically certain soil characteristics and rainfall. Incompatible soils include permafrost, sand ( $>70 \%$ sand fraction and $<15 \%$ clay fraction), organic soil (histosols or $>20 \%$ organic material dry mass), and rainfall $<400$ and $>1200 \mathrm{~mm} / \mathrm{yr}$, and representing limits to forage quantity and quality required to maintain large herbivores.

in the same place for decades to centuries (McNaughton 1984). With the inclusion of bioturbators, however, various patch-conversion mechanisms are possible, causing much more dynamic landscapes at different scales. When grazing mosaics mostly originate through water-infiltration feedbacks and/or irreversible soil changes, then such systems can be subject to landscape-scale catastrophic collapse when critical thresholds are exceeded (temporary high herbivore numbers or a drought), and subsequently lose their ecosystem functions and services for a long time (van de Koppel et al. 1997, Rietkerk et al. 2004, Kéfi et al. 2007). However, when bioturbation is indeed important, lawns and tall patches may shift back and forth, promoting a fast recovery after collapse and thus higher resilience. Specifically, it may explain why savanna systems dominated by large herbivores can experience tremendous year-to-year variation in key factors as rainfall, fire, and herbivore density, and still are able to retain their key features; i.e., often very rapidly bounce back from such events.

\section{Future OutLOOK}

Understanding the interplay between soil fauna, large grazers and consequences for vegetation community composition and structure is important for the basic ecological understanding of grazed ecosystems worldwide, providing invaluable tools for the management and conservation of grassland and grassland-shrubland ecosystems (Vitousek et al. 1997). Based on our global prediction and explicit set of environmental restrictions, we recommend further testing of our bioturbation-biocompaction model and comparative studies, thus providing the basis for a meta-analysis that will enable spatial plant-herbivore interaction hypothesis to extend across scales of ecological organization. Following up on our suggestion that this bioturbation-biocompaction mechanism can promote ecosystem resilience (ValienteBanuet et al. 2006, Soliveres et al. 2015), more work is required to explore the behavior of this type of heterogeneous ecosystems close to tipping points (Luck et al. 2003, Lorenzen et al. 2011, Seifan et al. 2011).

\section{ACKNOWLEDGMents}

We wish to thank Matty P. Berg, Maarten Schrama, Owen Howison, Rutger Steever, Michiel P. Veldhuis, and Jan P. Bakker for fruitful discussions of these ideas. We thank Dick Visser for the layout of the figures. The manuscript benefited greatly from the comments of Jordi Bascompte and three anonymous referees.

\section{Literature Cited}

Abdelmagid, A. H., G. E. Schuman, and R. H. Hart. 1987. Soil bulk-density and water infiltration as affected by grazing system. Journal of Range Management 40:307-309.

Andresen, H., J. Bakker, M. Brongers, B. Heydemann, and U. Irmler. 1990. Long-term changes of salt marsh communities by cattle grazing. Vegetatio 89:137-148. 
Archibald, S., W. J. Bond, W. D. Stock, and D. H. K. Fairbanks 2005. Shaping the landscape: fire grazer interactions in an African savanna. Ecological Applications 15:96-109.

Bakker, E., H. Olff, M. Boekhoff, J. Gleichman, and F. Berendse. 2004. Impact of herbivores on nitrogen cycling: contrasting effects of small and large species. Oecologia 138:91-101.

Bardgett, R. D., and D. A. Wardle. 2003. Herbivore-mediated linkages between aboveground and belowground communities. Ecology 84:2258-2268.

Belsky, A. J. 1986. Population and community processes in a mosaic grassland in the Serengeti, Tanzania. Journal of Ecology 74:841-856.

Bergvall, U. A., P. Rautio, K. Kesti, J. Tuomi, and O. Leimar. 2006. Associational effects of plant defences in relation to within-and between-patch food choice by a mammalian herbivore: neighbour contrast susceptibility and defence. Oecologia 147:253-260.

Bertness, M. D., and R. Callaway. 1994. Positive interactions in communities. Trends in Ecology \& Evolution 9:191-193.

Bos, D., J. Van De Koppel, and F. J. Weissing. 2004. Darkbellied Brent geese aggregate to cope with increased levels of primary production. Oikos 107:485-496.

Bump, J. K., R. O. Peterson, and J. A. Vucetich. 2009. Wolves modulate soil nutrient heterogeneity and foliar nitrogen by configuring the distribution of ungulate carcasses. Ecology 90:3159-3167.

Butler, D. R. 1995. Zoogeomorphology; Animals as geomorphic agents. Cambridge University Press, Cambridge, UK

Butterfield, N. J. 2011. Animals and the invention of the Phanerozoic Earth system. Trends in Ecology \& Evolution 26:81-87.

Cid, M. S., and M. A. Brizuela. 1998. Heterogeneity in tall fescue pastures created and sustained by cattle grazing. Journal of Range Management 51:644-649.

Crain, C. M. 2008. Interactions between marsh plant species vary in direction and strength depending on environmental and consumer context. Journal of Ecology 96:166-173.

Cromsigt, J. P., and H. Olff. 2008. Dynamics of grazing lawn formation: an experimental test of the role of scale-dependent processes. Oikos 117:1444-1452.

Cumming, D. H. M., and G. S. Cumming. 2003. Ungulate community structure and ecological processes: body size, hoof area and trampling in African savannas. Oecologia 134:560-568.

Curry, J., and K. Boyle. 1987. Growth rates, establishment, and effects on herbage yield of introduced earthworms in grassland on reclaimed cutover peat. Biology and Fertility of Soils 3:95-98.

Darwin, C. 1881. The formation of vegetable mould, through the action of worms: with observations on their habits. John Murray, London, UK.

Dexter, A. 1991. Amelioration of soil by natural processes. Soil and Tillage Research 20:87-100.

Donkor, N., J. Gedir, R. Hudson, E. Bork, D. Chanasyk, and M. Naeth. 2002. Impacts of grazing systems on soil compaction and pasture production in Alberta. Canadian Journal of Soil Science 82:1-8.

Dumont, B., A. Rook, C. Coran, and K. U. Röver. 2007. Effects of livestock breed and grazing intensity on biodiversity and production in grazing systems. 2. Diet selection. Grass and Forage Science 62:159-171.

Dyer, M., C. Turner, and T. Seastedt. 1993. Herbivory and its consequences. Ecological Applications 3:10-16.

Frank, D. A., S. J. McNaughton, and B. F. Tracy. 1998. The ecology of the earth's grazing ecosystems. BioScience 48:513-521.

Fryxell, J. M. 1991. Forage quality and aggregation by large herbivores. American Naturalist 138:478-498.
Fryxell, J. M., and A. R. E. Sinclair. 1988. Causes and consequences of migration by large herbivores. Trends in Ecology \& Evolution 3:237-241.

Garibaldi, L. A., M. Semmartin, and E. J. Chaneton. 2007. Grazing-induced changes in plant composition affect litter quality and nutrient cycling in flooding Pampa grasslands. Oecologia 151:650-662.

Grant, C., and M. Scholes. 2006. The importance of nutrient hot-spots in the conservation and management of large wild mammalian herbivores in semi-arid savannas. Biological Conservation 130:426-437.

Hacker, S. D., and M. D. Bertness. 1999. Experimental evidence for factors maintaining plant species diversity in a New England salt marsh. Ecology 80:2064-2073.

Hagenah, N., H. H. Prins, and H. Olff. 2009. Effects of large herbivores on murid rodents in a South African savanna. Journal of Tropical Ecology 25:483-492.

Hijmans, R. J., S. E. Cameron, J. L. Parra, P. G. Jones, and A. Jarvis. 2005. Very high resolution interpolated climate surfaces for global land areas. International Journal of Climatology 25:1965-1978.

HilleRisLambers, R., M. Rietkerk, F. van den Bosch, H. H. Prins, and H. de Kroon. 2001. Vegetation pattern formation in semi-arid grazing systems. Ecology 82:50-61.

Hoorman, J. J., J. C. De Moraes Sa, and R. Reeder. 2009. The biology of soil compaction. Agriculture and Natural Resources, The Ohio State University, Columbus, Ohio, USA.

Hopcraft, J. G. C., H. Olff, and A. Sinclair. 2010. Herbivores, resources and risks: alternating regulation along primary environmental gradients in savannas. Trends in Ecology \& Evolution 25:119-128.

Howison, R. A., M. P. Berg, C. Smit, K. van Dijk, and H. Olff. 2016a. The importance of coprophagous macrodetritivores for the maintenance of vegetation heterogeneity in grazing ecosystems. Ecosystems 19:674-684.

Howison, R. A., H. Olff, R. Steever, and C. Smit. 2015. Large herbivores change the direction of interactions within plant communities along a salt marsh stress gradient. Journal of Vegetation Science 26:1159-1170.

Howison, R. A., H. Olff, M. E. B. van Puijenbroek, and C. Smit. 2016b. Facultative grazing and bioturbation by macrodetritivores alter saltmarsh plant-plant interactions under stress. Journal of Ecology 104:1149-1157.

Iason, G. R., and S. E. van Wieren. 1999. Digestive and ingestive adaptations of mammalian herbivores to low quality forage. Pages 337-369 in H. Olff, V. K. Brown, and R. H. Drent, editors. Herbivores: between plants and herbivores. 38th Symposium of the British Ecological Society. Blackwell Science, Oxford, UK

Issa, O. M., J. Trichet, C. Défarge, A. Couté, and C. Valentin. 1999. Morphology and microstructure of microbiotic soil crusts on a tiger bush sequence (Niger, Sahel). Catena $37: 175-196$

Jefferies, R. L., A. P. Jano, and K. F. Abraham. 2006. A biotic agent promotes large-scale catastrophic change in the coastal marshes of Hudson Bay. Journal of Ecology 94:234-242.

Jones, C. G., J. H. Lawton, and M. Shachak. 1994. Organisms as ecosystem engineers. Oikos 69:373-386.

Joschko, M., H. Diestel, and O. Larink. 1989. Assessment of earthworm burrowing efficiency in compacted soil with a combination of morphological and soil physical measurements. Biology and Fertility of Soils 8:191-196.

Jouquet, P., J. Dauber, J. Lagerlöf, P. Lavelle, and M. Lepage. 2006. Soil invertebrates as ecosystem engineers: intended and accidental effects on soil and feedback loops. Applied Soil Ecology 32:153-164. 
Kéfi, S., M. Rietkerk, C. L. Alados, Y. Pueyo, V. P. Papanastasis, A. ElAich, and P. C. de Ruiter. 2007. Spatial vegetation patterns and imminent desertification in Mediterranean arid ecosystems. Nature 449:213-217.

Klausmeier, C. A. 1999. Regular and irregular patterns in semiarid vegetation. Science 284:1826-1828.

Knapp, A. K., J. M. Blair, J. M. Briggs, S. L. Collins, D. C. Hartnett, L. C. Johnson, and E. G. Towne. 1999. The keystone role of bison in North American tallgrass prairie. BioScience 49:39-50.

Kristensen, E., G. Penha-Lopes, M. Delefosse, T. B. Valdemarsen, C. O. Quintana, and G. T. Banta. 2012. What is bioturbation? The need for a precise definition for fauna in aquatic sciences. Marine Ecology Progress Series 446:285-302.

Kuijper, D. P. J., and J. Bakker. 2003. Large-scale effects of a small herbivore on salt-marsh vegetation succession - a comparative study on three Wadden Sea islands. Journal of Coastal Conservation 9:179-188

Lawton, J. H. 1994. What do species do in ecosystems. Oikos 71:367-374.

Lehmann, C. E., S. A. Archibald, W. A. Hoffmann, and W. J. Bond. 2011. Deciphering the distribution of the savanna biome. New Phytologist 191:197-209.

Looijen, R. C., and J. P. Bakker. 1987. Utilization of different salt-marsh plant communities by cattle and geese. Pages 51-64 in A. H. Huiskes, C. W. P. M. Blom, and J. Rozema, editors. Vegetation between land and sea. Dr. W. Junk Publishers, Boston, Massachusetts, USA.

Lopez, G., J. Levinton, and L. Slobodkin. 1977. The effect of grazing by the detritivore Orchestia grillus on Spartina litter and its associated microbial community. Oecologia 30:111-127.

Lorenzen, E. D., D. Nogués-Bravo, L. Orlando, J. Weinstock, J. Binladen, K. A. Marske, A. Ugan, M. K. Borregaard, M. T. P. Gilbert, and R. Nielsen. 2011. Species-specific responses of late quaternary megafauna to climate and humans. Nature 479:359-364.

Luck, G. W., G. C. Daily, and P. R. Ehrlich. 2003. Population diversity and ecosystem services. Trends in Ecology \& Evolution 18:331-336.

Mack, R. N., and J. N. Thompson. 1982. Evolution in steppe with few large, hooved mammals. American Naturalist 19:757-773.

Maestre, F. T., R. M. Callaway, F. Valladares, and C. J. Lortie. 2009. Refining the stress-gradient hypothesis for competition and facilitation in plant communities. Journal of Ecology 97:199-205.

Maestre, F. T., and A. Escudero. 2010. Is the patch size distribution of vegetation a suitable indicator of desertification processes? Reply. Ecology 91:3742-3745.

McLaren, J., and R. Jefferies. 2004. Initiation and maintenance of vegetation mosaics in an Arctic salt marsh. Journal of Ecology 92:648-660.

McNaughton, S. J. 1984. Grazing lawns animals in herds plant form and coevolution. American Naturalist 124:863-886.

McNaughton, S. J., M. Oesterheld, D. A. Frank, and K. J. Williams. 1989. Ecosystem-level patterns of primary production and herbivory in terrestrial habitats. Nature 341:142-144.

Meysman, F. J. R., J. J. Middelburg, and C. H. R. Heip. 2006. Bioturbation: a fresh look at Darwin's last idea. Trends in Ecology \& Evolution 21:688-695.

Mikola, J., H. Setälä, P. Virkajärvi, K. Saarijärvi, K. Ilmarinen, W. Voigt, and M. Vestberg. 2009. Defoliation and patchy nutrient return drive grazing effects on plant and soil properties in a dairy cow pasture. Ecological Monographs 79:221-244.

Milchunas, D., O. Sala, and W. K. Lauenroth. 1988. A generalized model of the effects of grazing by large herbivores on grassland community structure. American Naturalist 132:87-106.
Nachtergaele, F., and N. Batjes. 2012. Harmonized world soil database. FAO, Rome, Italy and IIASA, Laxenburg, Austria.

O'Connor, T. 1994. Composition and population responses of an African savanna grassland to rainfall and grazing. Journal of Applied Ecology 31:155-171.

Olff, H., J. De Leeuw, J. Bakker, R. Platerink, and H. Van Wijnen. 1997. Vegetation succession and herbivory in a salt marsh: changes induced by sea level rise and silt deposition along an elevational gradient. Journal of Ecology 85:799-814.

Olff, H., M. E. Ritchie, and H. H. Prins. 2002. Global environmental controls of diversity in large herbivores. Nature 415:901-904.

Rietkerk, M., S. C. Dekker, P. C. de Ruiter, and J. van de Koppel. 2004. Self-organized patchiness and catastrophic shifts in ecosystems. Science 305:1926-1929.

Rietkerk, M., P. Ketner, J. Burger, B. Hoorens, and H. Olff. 2000. Multiscale soil and vegetation patchiness along a gradient of herbivore impact in a semi-arid grazing system in West Africa. Plant Ecology 148:207-224.

Rietkerk, M., and J. Van de Koppel. 1997. Alternate stable states and threshold effects in semi-arid grazing systems. Oikos 79:69-76.

Ruess, R. W., and S. J. McNaughton. 1987. Grazing and the dynamics of nutrient and energy regulated microbial processes in the Serengeti Tanzania Kenya grasslands. Oikos 49:101-110.

Sankaran, M., N. P. Hanan, R. L. Scholes, J. Ratnam, D. J. Augustine, B. S. Cade, J. Gignoux, S. I. Higgins, X. Le Roux, F. Ludwig, J. Ardo, F. Banyikwa, A. Bronn, G. Bucini, K. K. Caylor, M. B. Coughenour, A. Diouf, W. Ekaya, C. J. Feral, E. C. February, P. G. H. Frost, H. Pierre, H. Hrabar, K. L. Metzger, H. H. T. Prins, S. Ringrose, W. Sea, J. Tews, J. Worden, and N. Zambatis. 2005. Determinants of woody cover in savannas. Nature 438:846-849.

Scheu, S. 2003. Effects of earthworms on plant growth: patterns and perspectives. Pedobiologia 47:846-856.

Schrama, M., M. P. Berg, and H. Olff. 2012a. Ecosystem assembly rules: the interplay of green and brown webs during salt marsh succession. Ecology 93:2353-2364.

Schrama, M., P. Heijning, J. Bakker, H. Van Wijnen, M. Berg, and H. Olff. 2012b. Herbivore trampling as an alternative pathway for explaining differences in nitrogen mineralization in moist grasslands. Oecologia 172:231-243.

Schrama, M., L. van Boheemen, H. Olff, and M. P. Berg. 2015. How the litter-feeding bioturbator Orchestia gammarellus promotes late successional salt marsh vegetation. Journal of Ecology 103:915-924.

Schrama, M., G. F. Veen, E. S. Bakker, J. L. Ruifrok, J. P. Bakker, and H. Olff. 2013. An integrated perspective to explain nitrogen mineralization in grazed ecosystems. Perspectives in Plant Ecology, Evolution and Systematics 15:32-44.

Seifan, M., T. Seifan, F. Jeltsch, and K. Tielbörger. 2011. Combined disturbances and the role of their spatial and temporal properties in shaping community structure. Perspectives in Plant Ecology, Evolution and Systematics 14:217-229.

Sharma, S., K. Pradhan, S. Satya, and P. Vasudevan. 2005. Potentiality of earthworms for waste management and in other uses - a review. Journal of American Science 1:4-16.

Smit, C., M. Rietkerk, and M. J. Wassen. 2009. Inclusion of biotic stress (consumer pressure) alters predictions from the stress gradient hypothesis. Journal of Ecology 97:1215-1219.

Soliveres, S., C. Smit, and F. Maestre. 2015. Moving forward on facilitation research: response to changing environments and effects on the diversity, functioning and evolution of plant communities. Biological Reviews 90:297-313.

Syers, J., and J. Springett. 1984. Earthworms and soil fertility. Plant and Soil 76:93-104. 
Tarnocai, C., J. Canadell, E. Schuur, P. Kuhry, G. Mazhitova, and S. Zimov. 2009. Soil organic carbon pools in the northern circumpolar permafrost region. Global Biogeochemical Cycles 23:1-11.

Valiente-Banuet, A., A. V. Rumebe, M. Verdú, and R. M. Callaway. 2006. Modern quaternary plant lineages promote diversity through facilitation of ancient tertiary lineages. Proceedings of the National Academy of Sciences USA 103 : 16812-16817.

Van de Koppel, J., R. D. Bardgett, J. Bengtsson, C. RodriguezBarrueco, M. Rietkerk, M. J. Wassen, and V. Wolters. 2005. The effects of spatial scale on trophic interactions. Ecosystems 8:801-807.

van de Koppel, J., J. Huisman, R. van der Wal, and H. Olff. 1996. Patterns of herbivory along a productivity gradient: an empirical and theoretical investigation. Ecology 77:736-745.

van de Koppel, J., M. Rietkerk, and F. J. Weissing. 1997. Catastrophic vegetation shifts and soil degradation in terrestrial grazing systems. Trends in Ecology \& Evolution 12:352-356.

van der Plas, F., P. Zeinstra, M. Veldhuis, R. Fokkema, E. Tielens, R. Howison, and H. Olff. 2013. Responses of savanna lawn and bunch grasses to water limitation. Plant Ecology 214:1157-1168.

van der Wal, R., J. van de Koppel, and M. Sagel. 1998. On the relation between herbivore foraging efficiency and plant standing crop: an experiment with barnacle geese. Oikos 82: 123-130.

van Klink, R., M. Schrama, S. Nolte, J. P. Bakker, M. F. WallisDeVries, and M. P. Berg. 2015. Defoliation and soil compaction jointly drive large-herbivore grazing effects on plants and soil arthropods on clay soil. Ecosystems 18:671-685.

Veldhuis, M. P., R. A. Howison, R. W. Fokkema, E. Tielens, and H. Olff. 2014. A novel mechanism for grazing lawn formation: large herbivore-induced modification of the plantsoil water balance. Journal of Ecology 102:1506-1517.

Verweij, R. J. T., J. Verrelst, P. E. Loth, I. M. A. Heitkönig, and A. M. H. Brunsting. 2006. Grazing lawns contribute to the subsistence of mesoherbivores on dystrophic savannas. Oikos 114:108-116.

Vitousek, P. M., H. A. Mooney, J. Lubchenco, and J. M. Melillo. 1997. Human domination of Earth's ecosystems. Science 277:494-499.

Wilkinson, M. T., P. J. Richards, and G. S. Humphreys. 2009. Breaking ground: pedological, geological, and ecological implications of soil bioturbation. Earth-Science Reviews 97: 257-272.

Young, T. P., N. Patridge, and A. Macrae. 1995. Long-term glades in acacia bushland and their edge effects in Laikipia, Kenya. Ecological Applications 5:97-108.

\section{Data Availability}

Data associated with this paper are available from the Dryad Digital Repository: https://doi.org/10.5061/dryad.3f $2 \mathrm{j} 7$ or from the Groningen University Data Respository http://hdl.handle.net/10411/CIYMZG 